\title{
Conflitos vivenciados pelas adolescentes com a descoberta da gravidez
}

\section{Thereza Maria Magalhães Moreira ${ }^{1}$, Danielle de Sousa Viana ${ }^{2}$, Maria Veraci Oliveira Queiroz ${ }^{3}$, Maria Salete Bessa Jorge ${ }^{4}$}

\section{RESUMO}

O estudo investigou os conflitos vivenciados pelas adolescentes com a descoberta da gravidez. A pesquisa descritiva com 12 adolescentes grávidas foi realizada em Jucás-Ceará. Os achados foram analisados após agrupamento em categorias temáticas emergidas das falas das entrevistadas ao responderem à indagação: Como tem vivenciado a gravidez na adolescência? Verificou-se que a gravidez era vista como um problema indesejado e que as adolescentes tinham medo de partilhar sua descoberta com a família ou o companheiro. Foram observadas reações dos pais ou responsáveis e o baixo nível socioeconômico como determinantes da não aceitação da gestação. Concluiu-se que a gravidez na adolescência constitui-se um problema de Saúde Pública, que deve ser visualizado amplamente, percebendo-se a adolescente e seus problemas cotidianos.

\section{DESCRITORES}

Gravidez na adolescência.

Comportamento do adolescente.

Saúde pública.

\begin{abstract}
This descriptive research with 12 pregnant teenagers was conducted in Jucás, State of Ceará. The findings were analyzed after being grouped in the thematic categories that emerged from the interviews carried out with the young women, who were asked to answer the question: How have you been experiencing pregnancy in adolescence? It was verified that pregnancy was seen as an undesired problem and that the pregnant teenagers were afraid to share their state with their family or partner. It was observed that the reaction from parents or legal guardians and the low socio-economic level were determinant for the non-acceptance of pregnancy. It was concluded that pregnancy in adolescence is an issue that belong to the realm of Public Health, and that it must be seen as part of a wider picture, in which the adolescents and their daily problems need to be considered.
\end{abstract}

\section{KEY WORDS}

Pregnancy in adolescence.

Adolescent behavior.

Public health.

\begin{abstract}
RESUMEN
En el estudio se investigó los conflictos vivenciados por las adolescentes al descubrir su embarazo. Esta investigación descriptiva realizada con 12 adolescentes embarazadas se llevó a cabo en Jucás-Ceará. Los hallazgos fueron analizados después del agrupamiento en categorías temáticas que emergieron de los discursos de las entrevistadas al responder a la pregunta: Cómo has vivenciado el embarazo en la adolescencia? Se verificó que el embarazo era visto como un problema indeseado y que las adolescentes tenían miedo de compartir su descubrimiento con la familia o el compañero. Fueron observadas reacciones de los padres o responsables y el bajo nivel socioeconómico como determinantes de la no aceptación de la gestación. Se concluyó que el embarazo en la adolescencia se constituye en un problema de Salud Pública, que debe ser visualizado ampliamente, percibiéndose a la adolescente y sus problemas cotidianos.
\end{abstract}

\section{DESCRIPTORES}

Embarazo en adolescencia.

Conducta del adolescente.

Salud pública.

\footnotetext{
${ }^{1}$ Enfermeira. Doutora em Enfermagem. Docente do curso de graduação em Enfermagem e do Mestrado Acadêmico em Cuidados Clínicos em Saúde (CMACCLIS) da Universidade Estadual do Ceará (UECE). Fortaleza, CE, Brasil. tmoreira@uece.br ${ }^{2}$ Enfermeira. Especialista em Saúde da Família. masabejo@uece.br ${ }^{3}$ Enfermeira. Doutora em Enfermagem. Professor Adjunto da Universidade Estadual do Ceará. Membro do Grupo de Pesquisa Saúde Mental, Família, Práticas de Saúde e Enfermagem. Fortaleza, CE, Brasil.veracioq@hotmail.com ${ }^{4}$ Doutora em Enfermagem pela Escola de Enfermagem de Ribeirão Preto da Universidade de São Paulo (EERP/USP). Professor Titular da Universidade Estadual do Ceará. Líder do Grupo de Pesquisa Saúde Mental, Família, Práticas de Saúde e Enfermagem. Docente do Mestrado em Cuidados Clínicos em Saúde e Enfermagem. Pesquisadora do CNPq. Fortaleza, CE, Brasil.masabejo@bol.com.br
}

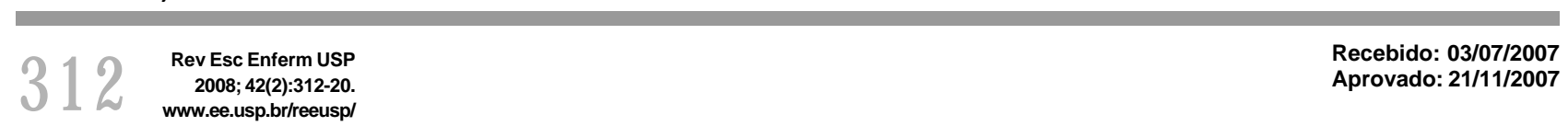




\section{INTRODUÇÃO}

A adolescência delimita a transição da infância à idade adulta, cronologicamente abrangendo dos 10 aos 19 anos $^{(1)}$. Trata-se de um período de profundas modificações, marcado pela transição entre a puberdade e o estado adulto do desenvolvimento. Nessa fase, a perda do papel infantil gera inquietação, ansiedade e insegurança frente à descoberta de um novo mundo.

Enquanto parte inerente do ciclo de vida humano, a adolescência constitui-se de características próprias, que a diferenciam das demais faixas etárias. Este é um período confuso, de contradições, de formação da identidade e da auto-estima. É quando se deve deixar de ser criança para entrar no mundo adulto, repleto de responsabilidades e cobranças, mundo este tão desejado pela sensação da liberdade a ser adquirida, mas também tão temido(2).

$\mathrm{Na}$ adolescência, há a descoberta do corpo e dos órgãos sexuais. Nas meninas aumenta os seios, os quadris, a distribuição dos pêlos e ocorre a menarca. Esse amadurecimento físico se dá em decorrência dos hormônios sexuais e do crescimento. Na busca do prazer, do conhecimento de si e de auto-afirmação, os jovens, não raro, tornam-se rebeldes e com acentuado comprometimento de humor, porquanto vivem em constantes conflitos. $\mathrm{Na}$ realidade brasilei$\mathrm{ra}$, muitas vezes a adolescente, além dos conflitos próprios da faixa etária, vê-se com nú outras questões conflituosas, como a ocorrência de uma gravidez.

A gravidezé um período de grandes transformações para a mulher. Seu corpo se modifica e seus níveis de hormônios se alteram para a manutenção do feto. Com tantas novidades, essa fase pode acabar gerando dúvidas e sentimentos de fragilidade, insegurança e ansiedade na futura mamãe. Alguns dos principais temores são alterações na auto-imagem corporal e não ter uma criança saudável. Outros temores são relacionados ao feto e à função de gerar, nutrir e parir. Tais temores podem desencadear fases de irritabilidade e de instabilidade de humor na grávida.

A gravidez é um período de transição biologicamente determinado, caracterizado por mudanças metabólicas complexas e por grandes perspectivas de mudanças no papel social, na necessidade de novas adaptações, reajustamentos intrapessoais e mudanças de identidade ${ }^{(3)}$.

Atualmente, os índices de atendimento do Sistema Único de Saúde (SUS) demonstram o crescimento do número de internações para atendimento obstétrico nas faixas etárias de 10 a 14, 15 a 19 e 20 a 24 anos. As internações por gravidez, parto e puerpério correspondem a $37 \%$ das internações entre mulheres de 10 a 19 anos no SUS ${ }^{(4)}$. No Ceará, dados divulgados pela Secretaria da Saúde do Es- tado mostram que, de cada 1000 adolescentes entre $10 \mathrm{e}$ 19 anos, 42,9\% engravidaram em 2001 , e que $42,3 \%$ dos municípios do Estado apresentaram casos acima do estipulado(5).

0 interesse por eleger mães adolescentes para o estudo foi despertado em 2000, com o ingresso de uma das autoras no Programa Saúde da Família (PSF) de CariúsCeará, quando constatou a alta incidência de mães adolescentes. Atualmente, atuando no PSF de Jucás-Ceará, continua observando alto número de gravidezes entre adolescentes. Embora essa observação tenha se dado de forma empírica, o fato direcionou o olhar ao seguinte questionamento: Quais os conflitos comumente vivenciados pelas adolescentes com a descoberta da gravidez? Ante tal questionamento, foi realizado este estudo objetivando identificar os conflitos enfrentados pelas adolescentes atendidas em uma unidade de saúde após a descoberta da gravidez.

É sabido que existem vários trabalhos publicados acerca do fenômeno em pauta. Entretanto, cada vez que pesquisamos, uma faceta do tema pesquisado se mostra, pois o conhecimento é dinâmico. Assim, é importante conhecer o mundo/vida das pessoas para quem trabalhamos, para que a nossa fala tenha sintonia com o nosso fazer.

Este estudo revela-se de importância para a enfermagem e demais profissionais da saúde porque fornece subsídios acerca dos conflitos enfrentados pelas adolescentes grávidas e, assim, pode possibilitar uma prática mais pautada na realidade vivenciada por essas jovens.

\section{REVISÃO DA LITERATURA}

\section{0 despertarda adolescência}

A adolescência é um período de mudanças, ocasionadas por sua especial sinergia de fatores biológicos, psíquicos, sociais e culturais. Nesta fase, 0 jovem se vê em meio a novas relações com a família, o meio em que vive, consigo mesmo e com os outros adolescentes ${ }^{(6)}$. É nesse período da vida que ocorre a transição de um estado de dependência para outro de relativa independência ${ }^{(7)}$.

Sendo a adolescência um processo de desenvolvimento biopsicossocial, pode ser marcada por crises, dificuldades, mal-estar e angústia. Ao abandonar a condição infantil e buscar 0 ingresso no mundo adulto, 0 adolescente sofre acréscimos em seu rendimento psíquico. 0 intelecto, por exemplo, apresenta maior eficácia, rapidez e elaborações mais complexas, havendo acréscimo no seu desempenho global. Dessa forma, 0 adolescente pode formar condições de altivez e independência da experiência dos mais velhos. Achando que podem tudo, os adolescen- 
tes se rebelam e começam a elaborar valores inusitados, muitas vezes contrários aos até então tidos como corretos. Aqui são elaborados questionamentos dos modelos prescritos pela sociedade. É nessa fase que tendem a não mais aceitar normas. Essa rebeldia integra a construção da identidade juvenil e é fundamental a seu desenvolvimento humano. Quando essa disputa não se dá normalmente, geram-se problemas na adolescência que podem se estender à vida adulta, sendo difícil instituir um limiar entre normalidade e patologia hebiátrica. Um equilíbrio estável nesse estágio seria anormal(8).

Nesse período de disputa, as figuras de autoridade serão os alvos preferidos de contestação do adolescente. Aqui se questiona a autoridade do juiz, do padre, do pastor, do professor, do pai, considerando-se que essa noção de autoridade dos adolescentes se atualiza continuamente, sendo o jovem cada vez mais influenciado pelo ambiente, uma vez que começa a se afastar da família. À medida que os vínculos sociais vão se expandindo e estabelecendo, um conjunto de novas características vai se tornando importante ao adolescente, desde as necessárias para aceitação pelo grupo, até as necessárias ao estilo que agrada a si e ao outro.

Acerca do desenvolvimento físico, as alterações físicas acontecem rapidamente na adolescência. 0 amadurecimento sexual ocorre com o desenvolvimento das características sexuais primárias e secundárias. As características primárias são alterações físicas e hormonais necessárias à reprodução, e as secundárias diferenciam externamente o sexo masculino do feminino(9).

Sobre o desenvolvimento psicossocial, na medida em que a idade adulta se aproxima, 0 adolescente deve estabelecer relacionamentos íntimos ou permanecer socialmente isolado. A obtenção da identidade sexual é intensificada pelas alterações físicas da puberdade. Também é influenciada por atitudes culturais, expectativas do comportamento sexual e modelos de papéis válidos. Os adolescentes procuram uma identidade de grupo porque necessitam de estima e aceitação. É comum, em grupos, uma semelhança no modo de vestir e falar ${ }^{(9)}$. A popularidade com o sexo oposto, assim como os do mesmo sexo, tornase importante durante a adolescência. A necessidade de identidade de grupo entra em conflito com a necessidade de uma identidade pessoal.

0 movimento de afastamento em direção aos relacionamentos intensos com colegas é contrastado com o movimento de afastamento dos pais. Apesar da independência financeira não ser a norma, muitos adolescentes trabalham e exercem maior controle sobre suas aquisições e atividades sociais se os pais não forem os únicos provedores de recurso financeiro ${ }^{(9-10)}$.

Sobre o desenvolvimento cognitivo, são capazes de realizar operações formais nas quais devem refletir sobre o pensamento e separar o real do possível. Isso significa que podem utilizar o raciocínio dedutivo mesmo em situações além de suas experiências concretas. Os adolescentes podem considerar a lógica de um problema independentemente de seu conteúdo. Podem até resolver problemas que requerem manipulação simultânea de diversos conceitos abstratos. 0 desenvolvimento dessa habilidade é importante para a busca da identidade ${ }^{(9)}$.

Tanto as habilidades cognitivas, como seu desempenho, variam amplamente entre os adolescentes. De fato, um adolescente pode atuar em diferentes níveis cognitivos em situações distintas. Estímulos passados, experiências e educação formal no uso da lógica, e estratégias dedutivas efetivas, assim como a situação individual influenciam a expressão cognitiva.

\section{A sexualidade na adolescência}

A sexualidade vivida pelo adolescente ganha feição do contexto social e cultural em que ele está inserido. A sexualidade é plasmada pela linguagem e valores vigentes em cada época. Não há determinação biológica que mantenha uma definição sexual.

Nos dias atuais, várias concepções e valores têm se modificado com a evolução do pensamento humano. Assim, é percebida de forma diversa a virgindade, o casamento, a maternidade, 0 amor, os papéis sexuais dentro das relações conjugais e sociais.

O conflito de gerações, a pressão social e a busca da identidade trazem ambigüidade e um problema comum aos jovens: 0 de lidar com suas mudanças corporais e conflitos interiores no campo da sexualidade. 0 sexo é uma função natural que existe desde o nascimento e varia de intensidade segundo o ciclo vital. A sexualidade representa uma característica humana, sendo complexa e diversa das diferentes formas de manifestação individual e social.

A sexualidade é um elemento importante para a análise da dinâmica do adolescente. As mudanças físicas que caracterizam a fase incluem alterações hormonais que, muitas vezes, provocam estados de excitação tidos como incontroláveis, resultando em uma intensificação da atividade de masturbação. Nessa fase, também ocorre a consolidação do tipo de atração sexual vivida pelo indivíduo.

$\mathrm{Na}$ atualidade, vê-se o exercício da sexualidade começando cada vez mais cedo, impulsionado pela imposição social que leva crianças a adolescerem precocemente e, de forma semelhante, leva os adolescentes a rapidamente ingressarem na vida adulta, mesmo não estando preparados psicologicamente. Dessa forma, a sexualidade pode ser pensada a partir de uma esfera na qual são construídas e transformadas relações sociais, culturais e políticas, pelos diferentes valores, atitudes e padrões de comportamentos existentes na sociedade moderna. 0 adolescente contemporâneo vive sua sexualidade em meio às referências que invadem seu imaginário. Ele é ator integrante do 
espetáculo de nossa cultura e, como tal, é continuamente convocado a consumir imagens mais que a refletir, a elaborar ou a pensar. Dentro desse contexto de impulso social culminando em impulso sexual, espera-se que existam serviços e campanhas que orientem os jovens sobre seus problemas, conflitos ou questionamentos cotidianos durante essa fase de descobertas e modificações em todos os níveis, mas, infelizmente, esses recursos informativos são raros nos serviços públicos e até mesmo nos privados, como as escolas, os projetos sociais focalizados nesse período da vida, entre outros.

Esse despertar da sexualidade na adolescência é acompanhado por uma grande leva de desinformação. Os pais, por não disporem de informação ou por constrangimento em falar sobre sexo com seus filhos, acabam não cumprindo seu papel de educador. Assim, as famílias não transmitem a orientação sexual adequada, deixando 0 jovem em desvantagem.

0 direcionamento de diversos fatores, como o desconhecimento do corpo, a omissão da família/escola sobre assuntos pertinentes à adolescência, o pouco envolvimento dos serviços públicos, o bombardeamento ativo ao qual estão expostos pela mídia, com programas, novelas e até propagandas apelando ao sexo, fazem com que os jovens iniciem precocemente suas atividades sexuais, não cônscios das implicações de sua vida sexualmente ativa.

No entanto, existem diferenças básicas entre rapazes e moças, sobretudo, na forma de amar, desejar e no impulso sexual. Para os rapazes os impulsos sexuais são inicialmente bastante separados da noção de amor, enquanto para as moças 0 amor é prioridade ${ }^{(10)}$.

A realidade atual é que as relações sexuais se iniciam precocemente, com um número alarmante de gestações não desejadas e de doenças sexualmente transmissíveis (DST's), caracterizando a falta de conhecimento e informação dos adolescentes sobre 0 aparelho reprodutor e sua função, métodos contraceptivos e, principalmente, de atitudes concisas para um sexo seguro.

\section{A maternidade na adolescência}

A gravidez é uma transição que integra o desenvolvimento humano, mas revela complicações ao ocorrer na adolescência, pois envolve a necessidade de reestruturação e reajustamento em várias dimensões: em primeiro lugar, verificam-se mudanças na identidade e nova definição de papéis - a mulher passa a se olhar e a ser olhada de forma diferente. Evidentemente, o mesmo processo de mudança de papéis e identidade se verifica no homem e a paternidade também deve ser considerada como uma transição do seu desenvolvimento emocional.
A complexidade das mudanças provocada pela vinda de um bebê não se restringe às variáveis psicológicas e bioquímicas, pois os fatores socioeconômicos também são fundamentais. A gravidez na adolescência, antes um problema resolvido por um casamento às pressas ou exílio temporário com parentes em locais distantes, hoje ameaça o futuro dos jovens, considerando os riscos físi$\cos$, emocionais e sociais dela decorrentes. Atinge tamanha proporção que é considerada um problema social, revelando a prática de uma sexualidade não segura, com riscos de infecção pelo vírus da imunodeficiência humana (HIV) e outras doenças sexualmente transmissíveis.

A gestação em si é um momento delicado que requer atenção e, semelhante à adolescência, possui particularidades próprias. Quando se juntam estes dois momentos, adolescência e gravidez, é obtido um leque de transformações que levam a um turbilhão de emoções e acontecimentos.

Trabalhar com adolescentes grávidas implica em desafios para compreender este mundo repleto de subjetividade e contradições. Por isso, os profissionais que lidam com esta problemática precisam de um olhar mais apurado, detalhado e sensibilizado, para melhor aplicar os programas existentes e criar outros necessários para a resolução deste quadro que se agrava a cada dia. Em relação à vivência da gravidez e do parto é mister pensar que a mulher adolescente enfrenta um momento obscuro e merece ser compreendida. No desenrolar do trabalho de parto e no parto vivencia situações concretas em seu mundo-vida, um momento ímpar, singular para cada adolescente. É preciso que os profissionais de saúde interajam com respeito e dignidade que exige uma postura humana livre de preconceitos; um olhar compreensivo tentando estabelecer uma relação de empatia e de ajuda, o que pode amenizar a situação vivenciada ${ }^{(11)}$.

Durante os nove meses de gestação, as mulheres passam por mudanças fisio-psicológicas e requerem maior necessidade de afeto, carinho, cuidado e proteção. M as é nos dois últimos trimestres que as alterações psicológicas se acentuam. Isso porque no primeiro trimestre evidenciam-se transformações fisiológicas, como enjôos, mudanças no apetite, entre outros. 0 segundo trimestre da gestação é considerado o mais estável emocionalmente. Isto muito se deve aos movimentos fetais. No entanto, as alterações do desejo e do desempenho sexual tendem a surgir com maior intensidade. No terceiro trimestre, o nível de ansiedade tende a aumentar quanto mais se aproxima do parto e da rotina da vida após a chegada do bebê.

A gestação na adolescência é, de modo geral, enfrentada com dificuldade porque a gravidez nessas condições significa uma rápida passagem da situação de filha para 
mãe, do querer colo para dar colo. Nessa transição abrupta do seu papel de mulher, ainda em formação, para o de mulher-mãe, a adolescente vive uma situação conflituosa e, em muitos casos, penosa. A grande maioria é despreparada física, psicológica, social e economicamente para exercer o novo papel materno, o que compromete as condições para o assumir adequadamente e, associado à repressão familiar, contribui para que muitas fujam de casa e abandonem os estudos. Sem contar com as que são abandonadas pelo parceiro, muitas vezes também adolescente.

As perdas vivenciadas vão repercutir emocionalmente podendo levar a adolescente à somatização psicológica de alguns sinais e sintomas que porão em risco a gestação saudável.

Estudos evidenciam que a gravidez na adolescência tem assumido grandes proporções nos últimos anos, sendo considerada um grave problema de saúde pública. No Brasil existe tendência de queda nas taxas de fecundidade total, mas entre mulheres de 15 a 19 anos esse índice aumentou em 26\% de 1970 a 1991, e entre 1993 e 1998, houve incremento de $31 \%$ no percentual de partos entre meninas de 10 a 14 anos atendidas na rede do Sistema Único de Saúde-SUS(5).

Estima-se que no Brasil um milhão de nascidos vivos, a cada ano têm mães com idade entre 10 a 19 anos, o que corresponde a $20 \%$ do total de nascidos vivos no País ${ }^{(12)}$.

Além dos números crescentes, a faixa etária cada vez menor de meninas que engravidam chama a atenção da sociedade e do governo, mundialmente, gerando a criação de programas de atuação na saúde pública com pretensão de ampla cobertura e envolvimento de vários profissionais de saúde, dentre eles, o enfermeiro.

As adolescentes estão tendo sua primeira experiência sexual cada vez mais cedo. Conseqüentemente, meninas estão engravidando precocemente, entre 10 e 20 anos ${ }^{(5)}$, atropelando a juventude e entrando despreparadas físi$\mathrm{ca}$, emocional e financeiramente na fase adulta

Clinicamente, pode-se associar uma gravidez precoce com o aumento de intercorrências obstétricas e/ou neonatais, tais como: morte materna, índices de prematuridade, mortalidade neonatal e baixo peso de recémnascidos ${ }^{(13)}$.

A gravidez na adolescência não é de alto risco, contanto que a adolescente tenha um acompanhamento adequado, boa alimentação, cuidados higiênicos necessários e apoio emocional. Também não é um problema da sociedade moderna, porque em todas as épocas as mulheres engravidaram na adolescência. É um problema da sociedade moderna a gravidez indesejada na adolescência, que ocorre de forma desestruturada ${ }^{(14)}$. As nossas avós casavam adolescentes, mas tinham um lar e proventos necessários para criar seus filhos. Os filhos eram recebidos com sa- tisfação, porque a mulher era preparada desde o nascimento para casar e procriar. A adolescência da sociedade moderna tem outros sonhos e necessidades.

Quando a gestação é indesejada e sem apoio, muitas adolescentes recorrem à prática do aborto em condições impróprias e caracterizadas como ilegal na Constituição Brasileira. Só em 1998, mais de 50 mil adolescentes foram atendidas em hospitais públicos para curetagem pósaborto, sendo cerca de três mil realizados entre jovens com idade entre 10 e 14 anos $^{(4)}$.

Estudo realizado em Feira de Santana-Bahia verificou queda no número geral de procedimentos obstétricos, queda menor no número de abortos e aumento progressivo de abortos em adolescentes, sendo o tipo provocado representante de $55,2 \%$ do total das ocorrências ${ }^{(15)}$.

É necessária uma reflexão para se entenderem os motivos que levam essas meninas a engravidar, considerando esse acontecimento como multicausal. A gravidez na adolescência não pode ser vista como um fato isolado, mas como parte da busca da identidade da menina e de uma certa atitude de rebeldia diante da família e do contexto histórico-social amplo do qual faz parte. Vale, no entanto, saber que muitas meninas engravidam porque desejam, acreditam que é isso que o namorado quer, desejam a liberdade da casa dos pais, querem ser vistas como adultas, ou por outros motivos. Aliás, como fora citado, não se pode desprezar as mensagens passadas culturalmente.

\section{MÉTODO}

A pesquisa descritiva com abordagem qualitativa foi realizada na zona urbana do município de Jucás-Ceará, pertencente à região Centro-Sul, localizada a $417 \mathrm{~km}$ de Fortaleza.

A pesquisa qualitativa busca respostas para questões particulares. São estudos em que predomina o trabaIho com o material discursivo ou com outras formas de linguagem ${ }^{(16)}$.

A população do município em estudo é de aproximadamente 23 mil habitantes. A pesquisa foi realizada numa unidade de saúde onde atuam duas equipes do Programa Saúde da Família, na qual são atendidas mensalmente cerca de 200 mulheres. Destes atendimentos, 60\% são adolescentes. A unidade de saúde oferece atendimento aos grupos humanos por uma equipe multiprofissional composta por: odontólogo, clínico geral, pediatra, ginecologista obstetra, cardiologista, enfermeira, psicólogo, fonoaudiólogo e farmacêutico.

Foi realizado um estudo com 12 adolescentes grávidas (da zona urbana do município de Jucás-CE), cadastradas na unidade de saúde referida durante fevereiro a março de 2005. 
O estudo utilizou o critério da saturação dos achados para definir o período de coleta de dados. Para a coleta de dados, optou-se pela técnica de entrevista semiestruturada realizada por meio da questão norteadora: como tem vivenciado a gravidez na adolescência? A entrevista, definida como um encontro social, com empatia, intersubjetividade, intuição e imaginação(16), foi guiada por um roteiro contendo a referida questão. Utilizou-se também o diário de campo, para possibilitar o registro de observações e impressões da pesquisadora.

Conforme a Resolução n 196/96, do Conselho Nacional de Saúde, este projeto foi aprovado pelo Comitê de Ética em Pesquisa da Universidade Estadual do Ceará (Processo n. 04497584-8).

Os aspectos éticos pertinentes a pesquisas com seres humanos foram considerados ao longo do estudo. As adolescentes foram denominadas por nomes de flores para resguardar sua identidade. Essas adolescentes concordaram em participar do estudo e registraram sua anuência em um termo de consentimento livre e esclarecido. Quando menores de 18 anos, foi registrada também a anuência de seu responsável legal. No momento do estudo estavam conscientes, orientadas e em condições de serem entrevistadas.

Os dados foram processados e analisados em categorias de significados, buscando melhor compreender os problemas vivenciados pelas adolescentes com a descoberta da gravidez.

\section{RESULTADOS E DISCUSSÃO}

Compreende-se que, para as adolescentes grávidas, foram encontradas as seguintes categorias de análise, que traduzem o significado de alguns conflitos vivenciados:

- A gravidez como um problema indesejado.

- Medo de enfrentar a gravidez perante a família ou companheiro.

- Reações dos pais ou responsáveis diante da gravidez na adolescência.

- Baixo nível socioeconômico como determinante da não aceitação da gravidez.

A primeira categoria de significado - A gravidez como um problema indesejado - é expressa nos trechos dos depoimentos a seguir:

[...] nunca pensei que fosse acontecer comigo, tô sofrendo muito [...] (Margarida, 15 anos);

[...] fiquei louca, desesperada, a vontade que eu tinha era de matar, sei lá, vinha tanta coisa na minha cabeça, pela primeira vez tive um problema de gente grande [...] (Orquídea, 16 anos);

[...] pensei até em me matar, porque meu namorado não queria se juntar comigo, eu não podia dizer nada pra mãe e pior pro pai [...] (Dália, 18 anos).
A partir dos relatos das adolescentes, vislumbrou-se que a dimensão emocional é abalada e a gravidez vivida como momento de renúncias. É um corte em seu desenvolvimento, a perda de identidade, a interrupção nos estudos, a perda da confiabilidade da família, muitas vezes a perda do namorado, de expectativa de futuro e, por fim, a perda da proteção familiar.

A unidade de significado nos trechos dos depoimentos citados expressa bem a insatisfação da adolescente quando enfrenta uma gravidez ${ }^{(17)}$. Esta não se apresenta como ato gratificante, e sim como algo que traz desprazer, insegurança, medo e angústia, pois as mesmas, muitas vezes, são excluídas do convívio social e, por isso, se sentem mal-amadas e inseguras. Além disso, na gravidez, a muIher está vulnerável emocionalmente, portanto, ela necessita de apoio redobrado.

Nas falas registradas no diário de campo, viu-se que algumas adolescentes tiveram atitudes momentâneas que revelaram o desejo de provocar aborto ou suicídio e expressaram sentimentos de tristeza observados pela expressão facial de sofrimento, olhos cheios de lágrimas, não fixação do olhar, voz trêmula e em baixo tom.

Percebeu-se que, apesar desse sentimento ter emergido nos depoimentos, os fatores que levaram a tais comportamentos estavam ligados também a problemas socioeconômicos e ao relacionamento com o parceiro, bem como à maneira de elas se portarem diante das transformações do próprio corpo, das responsabilidades e das conseqüências de uma gravidez. Pelo observado em algumas falas das depoentes, muitas dependem financeira e psicologicamente de seus pais, têm pouco conhecimento sobre as transformações do seu corpo e, apesar de nada ou pouco terem aproveitado de sua pré-adolescência, já vão ter que se deparar com inúmeras limitações.

Existem também as que optam pelo aborto, haja vista não quererem abrir mão das festas, das noites de sono bem dormidas, do corpo esbelto.

Vê-se que há deficiência na orientação recebida dos pais e da escola sobre sexualidade.

Tem-se como segunda categoria de significado - Medo de enfrentar a gravidez perante a família ou companheiro, segundo depoimentos a seguir:

[...] o pior de tudo é o medo dos meus pais, meu Deus ele vai me matar [...] (Orquídea, 16 anos);

Meu maior medo era contar para meus pais, porque meu pai é daquele tipo antigo e até hoje me bate [...] (Papoula, 14 anos);

[...] Tava com medo do meu pai, que é bruto (Rosa, 16 anos);

[...] estou com medo não posso contar pros meus pais [...] se eu contar, minha tia vai fazer um inferno [...] (Copo-deleite, 14 anos). 
A gravidez indesejada na adolescência é profundamente perturbadora, é um susto existencial, um corte em seus planos de vida e, principalmente, um medo exacerbadoda reação dos pais e do companheiro, que é imprevisível|(18).

Conforme anotação do diário de campo e das entrevistas com as adolescentes, foi possível avaliar que a gravidez na adolescência traz, em muitas delas, o sentimento de medo. Este é vivenciado ao confessar a gravidez aos pais e companheiros, e, principalmente, ao confirmar a gravidez à figura paterna, referida como agressiva e ignorante. Elas afirmavam que era melhor contar à mãe, por ser mulher e entender essas coisas.

As que não tinham pais temiam revelar para as pessoas com quem viviam e tinham os seguintes pensamentos: Será que eu conto? E se eu contar, e ele não quiser mais viver comigo? Será que ele gosta de mim? Será que ele ia ficar triste ou alegre? Vários são os questionamentos que passam por suas mentes e ficam nesse impasse, qual seja, contar ou não a respeito de sua gravidez. M uitas, ao invés de contar, praticam o aborto, e nunca o companheiro irá ter conhecimentos de tal paternidade. Já outras, dispuseram-se a contar e a reação foi muito positiva. Foi mencionado, porém, em alguns depoimentos, que vários companheiros forjavam brigas, discussões, atingindo, assim, 0 objetivo, que era o término do relacionamento e a retirada da responsabilidade com a gravidez, resultando em mais um dos muitos problemas que as mães adolescentes têm de enfrentar.

A terceira categoria de significado compreende - Reação dos pais ou responsáveis diante da gravidez na adolescência, segundo os depoimentos:

O meu pai me botou pra fora de casa [...] (Margarida, 15 anos);

Não contei pra minha mãe, até que ela descobriu, ficou muito magoada comigo e hoje não me considera mais como filha [...] (Amélia, 16 anos);

O pai foi no meu trabalho e me deu uma surra na frente de todo mundo e me disse muita coisa humilhante [...] (Girassol, 15 anos);

[...] minha tia disse que eu ia ter que tirar essa criança [...] (Copo-de-leite, 14 anos).

Ora, na adolescência, a maternidade não é apenas um ato biológico-reprodutivo, mas um processo social que afeta significativamente as relações entre homem, muIher e membros familiares, definindo novas identidades sociais ${ }^{(10)}$.

Nas entrevistas com as adolescentes, verificou-se que os conflitos familiares relacionavam-se basicamente à desaprovação da gravidez e à desestruturação familiar.

Poucas são as famílias que aceitam a situação da gravidez na adolescência e procuram lidar com compreensão e afeto com as jovens mães e pais, respeitando suas limitações. No entanto, a grande maioria institui a experiência do casamento, mesmo que eles não o queiram, induzindo os jovens a abrir mão de seus desejos e expectativas. Outras impõem abortamento, abandono ou usam de violência. $E$ muitos pais expulsam sua filha de casa, aumentando os problemas que as jovens mães terão que enfrentar.

A quarta e última categoria de significado expressa Baixo nível socioeconômico como determinante da não aceitação da gravidez, de acordo com os depoimentos a seguir:

[...] eu nunca estudei e o único galho que arrumei foi de doméstica [...] (Papoula, 15 anos);

[...] depois da gravidez tive que ir trabalhar em Fortaleza pra me sustentar e foi muito difícil...só falta três semanas e eu não tenho como me sustentar [...] (Jasmim, 17 anos)

[...] parei de estudar e o que me sustenta é a aposentadoria da minha avó que mal dá pro tratamento dela, imagine pra mim e pro meu filho [...] (Girassol, 15 anos).

Os índices de gravidez na adolescência nas classes sociais desfavorecidas têm aumentado consideravelmente nas últimas décadas e a faixa etária é de mulheres cada vez mais jovens, configurando um problema de Saúde Pública(4). A falta de perspectiva de vida do adolescente, a baixa auto-estima, as más condições de educação e saúde e a falta de lazer contribuem para o aumento de casos de gravidez na adolescência. Outro fator relevante é a história familiar: a adolescente que engravida hoje é muitas vezes filha de adolescentes que engravidaram ou têm outra na família - uma tia, uma irmã ou uma vizinha.

De acordo com os diversos depoimentos, foi possível perceber que, das 12 mães adolescentes, todas tinham baixo nível socioeconômico e baixa escolaridade. Diante desta condição socioeconômica, duas optaram pelo aborto por não terem condições de criar seus filhos e seis se viam na condição de interromper seus estudos.

Os sistemas convencionais de ensino não dispõem de estrutura adequada para acolher uma adolescente grávida e, comumente, as induzem a interromper a escolarização.

A interrupção de seus estudos durante a gestação ou após o nascimento da criança acarreta perdas de oportunidades e piora da qualidade de vida no futuro. A mãe adolescente vê-se numa situação bastante perturbadora. Muitas das que foram entrevistadas não podiam contar para seus pais e estes, quando sabiam, expulsavam-nas de casa, ou usavam de agressões físicas. Quando contam para o companheiro, eles as abandonam. Muitas são obrigadas a parar de estudar, outras nunca estudaram. Diante dessa condição, elas encontram muitas dificuldades para conseguir emprego, pois as portas se fecham. 0 somatório desses problemas faz com que passe pela cabeça da adolescente o desejo de provocar aborto, suicí- 
dio ou entregar a criança para adoção. É um momento em que a jovem mãe necessita mais do que nunca de apoio, seja por parte da mãe, pai, companheiro, escola e/ou da sociedade em geral.

\section{CONSIDERAÇÕES FINAIS}

Durante o estudo, percebeu-se que os conflitos vivenciados pelas adolescentes com a descoberta da gravidez se dão na percepção dessa gestação como um acontecimento indesejado, no medo de enfrentar tal situação perante sua família ou companheiro, nas reações dos pais/ responsáveis com a descoberta da gravidez na adolescência e também são ressaltados no baixo nível socioeconômico familiar, determinantes da não aceitação da gravidez nessas adolescentes.

A adolescente grávida vive este momento de dúvidas, anseios e contestações, somado à aquisição de uma nova identidade para a qual pode não estar preparada e, sobretudo, à cobrança social que esse novo papel acarretará.

É evidente que a gravidez indesejada em adolescentes tem como principal conseqüência uma problemática nos níveis biológicos e psicossociais, tanto maior quanto menor a idade da gestante. Entre as conseqüências psicossociais, preocupa a interrupção da escolarização e da formação profissional. A pesquisa demonstra freqüente baixa escolaridade e falta de profissionalização entre as gestantes e mães adolescentes, o que dificulta a inserção no mercado competitivo de trabalho, implicando em empregos de baixa remuneração e desqualificação, colocando mães adolescentes e filhos em situação de risco social, se medidas de suporte não forem adotadas. Outra situação angustiante encontrada foi saber que, apesar das informações sobre métodos contraceptivos na mídia e dos programas existentes nas secretarias de saúde municipais, somente em um depoimento foi relatado conhecimento sobre camisinha. Sendo uma das pesquisadoras enfermeira que vivencia a ênfase dada a essa orientação no município, fica difícil acreditar que tal situação ainda venha a acontecer. É necessário, portanto, refletir sobre como estes programas estão sendo implementados na atenção básica.

A sociedade carece de sistemas educacionais que abranjam os adolescentes, em especial as jovens grávidas. Educadores, sanitaristas, líderes e pais freqüentemente têm pouca habilidade para conversar sobre a vida sexual na adolescência. Com isso, fornecem informações equivocadas ou geram constrangimento na discussão de tais assuntos. É necessário comunicar efetivamente aos jovens a necessidade de bem-estar físico, social e psicológico, e do estabelecimento de relações sólidas antes da maternidade ou paternidade.

A prevenção de gravidez indesejada na adolescência requer um esteio forte e uma educação formal bem delineada, que permita o recebimento de informações adequadas sobre educação sexual e métodos contraceptivos, além de requisitar um canal comunicacional aberto para que a adolescente possa expor suas idéias, temores, dúvidas e ter respaldo familiar na formação de sua personalidade.

Os programas para adolescentes que tratam de temas como sexualidade, gravidez, prevenção de doenças sexualmente transmissíveis e AIDS devem, sobretudo, considerar os aspectos sociais, culturais e econômicos da comunidade em que são desenvolvidos.

Os profissionais de saúde devem procurar estabelecer um relacionamento de confiança com essas adolescentes, a fim de prevenir na adolescente 0 desejo de provocar um aborto ou cometer suicídio. A adolescente deve receber apoio psicológico nesse momento, além de orientações sobre métodos contraceptivos, pré-natal e apoio da família, companheiro e sociedade. Além disso, é preciso ouvir e valorizar os sentimentos e preocupações dos jovens para conhecer o mundo adolescente: as pressões e os constrangimentos podem dar pistas das dificuldades que enfrentam na hora de optar e usar um método anticoncepcional, e dos entraves para a negociação dos métodos entre parceiros.

A partir do descrito, sugere-se à equipe de saúde realizar palestras dirigidas aos adolescentes, utilizando recursos didáticos que os sensibilizem para o uso de métodos contraceptivos; sensibilizar a equipe multiprofissional para o trabalho com adolescentes, incentivando seu maior empenho nos programas de assistência a esse grupo; e, desenvolver o trabalho com grupos de adolescentes a partir das necessidades apontadas por eles para que sejam atores ativos nesse processo, o que contribuirá na sua formação para a vida e o mundo. Para tanto, a equipe de saúde da família necessita estar capacitada e desenvolver continuamente ações de promoção da saúde junto a esta população, no que pesam as intervenções educativas realizadas pelo enfermeiro no cenário da saúde. 


\section{REFERÊNCIAS}

1. Ceará. Secretaria da Saúde do Estado. Atenção à Saúde dos Adolescentes e Jovens Cearenses. Normas operacionais para as equipes de saúde da família. Fortaleza; 2003.

2. Ramos FRS, Monticelli M, Nitschke RG, organizadoras. Projeto Acolher: um encontro da enfermagem com adolescentes brasileiros. Brasília: ABEn; 2000.

3. Melo LL, Lima MADS. Mulheres no segundo e terceiro trimestres de gravidez: suas alterações psicológicas. Rev Bras Enferm. 2000;53(1):81-6.

4. Brasil. Ministério da Saúde. Secretaria de Atenção à Saúde. Marco teórico e referencial: saúde sexual e saúde reprodutiva de adolescentes e jovens. Brasília; 2006.

5. Ceará. Secretaria da Saúde do Estado. Saúde reprodutiva e sexual: um manual para a atenção primária e secundária (nível ambulatorial). Fortaleza; 2002.

6. Takiuti AD. A saúde da mulher adolescente - 1993. In: Madeira FR, organizadora. Quem mandou nascer muIher? Estudos sobre crianças e adolescentes pobres no Brasil. Rio de Janeiro: Rosa dos Tempos; (c)1996. p. 21390.

7. Silva LMP. Violência doméstica contra a criança e o adolescente. Recife: EDUPE; 2002.

8. Freud A. O ego e os mecanismos de defesa. 3a ed. Rio de Janeiro: Civilização Brasileira; 1986.

9. Potter PA, Perry AG. Fundamentos de enfermagem. 6a ed. Rio de Janeiro: Mosby-Elsevier; 2006.

10. Tiba I. Adolescentes: quem ama, educa! São Paulo: Integrare; 2005.
11. Oliveira ZM LP, Madeira AMF. Vivenciando o parto humanizado: um estudo fenomenológico sob a ótica de adolescentes. Rev Esc Enferm USP. 2002;36(2):133-40

12. Ponte Júnior GM, Ximenes Neto FRG. Gravidez na adolescência no município de Santana do Acaraú - Ceará Brasil: uma análise das causas e riscos. Rev Eletrônica Enferm [periódico na Internet]. 2007 [citado 2007 out. 10];6(1):[cerca de 13 p.]. Disponível em: http:// www. fen. ufg.br/revista/revista6_1/pdf/f3_gravidez.pdf

13. Cunha SM, Bruno ZV. Efeito da gravidez na adolescência sobre os resultados perinatais em maternidades de nível terciário no ano de 2003 no estado do Ceará Brasil. Rev Bras Ginecol Obstet. 2006;28(7):431.

14. Dadoorian D. Pronta para voar: um novo olhar sobre a gravidez na adolescência. Rio de Janeiro: Rocco; 2000.

15. Souza VLC, Corrêa MSM, Souza SL, Beserra MA. O aborto entre adolescentes. Rev Lat Am Enferm. 2001;9(2):42-7.

16. Martins J, Bicudo MAV. A pesquisa qualitativa em psicologia: fundamentos e recursos básicos. 4ạ ed. São Paulo: Centauro; 2003.

17. Brasil. Ministério da Saúde. Secretaria de Atenção à Saúde. Saúde Integral de Adolescentes e Jovens. Orientações para a organização de serviços de saúde. Brasília; 2005.

18. Castro MG, Abramovay M, Silva LB. Juventudes e sexualidade. Brasília: UNESCO; 2004. 